\title{
The INSPIRE directive: some observations on the legal framework and implementation
}

\section{George Cho \& Joep Crompvoets}

To cite this article: George Cho \& Joep Crompvoets (2018): The INSPIRE directive: some observations on the legal framework and implementation, Survey Review, DOI: $10.1080 / 00396265.2018 .1454686$

To link to this article: https://doi.org/10.1080/00396265.2018.1454686

曲 Published online: 27 Mar 2018.

Submit your article to this journal $\pi$

山 Article views: 33

View Crossmark data ¿ 


\title{
The INSPIRE directive: some observations on the legal framework and implementation
}

\author{
George Cho $\oplus^{1}$ and Joep Crompvoets $\odot^{2}$
}

The observation that spatial and environmental data relating to specific locations or geographic areas in the European Union (EU) have been difficult to find online is undisputed. Whether the EU INSPIRE Directive of 2007 which establishes an infrastructure to enable the sharing of spatial data and services to support European and national environmental policies will achieve its objectives is a topic of debate. The INSPIRE Directive was conceived and implemented to address identifiable challenges relating to environmental policies and data. Before the complete implementation of the Directive, it may be necessary to reflect on what progress have been achieved at a legal and policy level. The central argument of this paper is that legal and policy issues may have hindered the rapid and smooth implementation of the Directive. The implementation of the legal framework of the Directive provides salutary lessons. Evaluation reports from the European Commission and the four case studies demonstrably paint an encouraging future. The conclusion is that INSPIRE should foster good governance, use and sharing of environmental data and information for the common good of all Europeans.

Keywords: INSPIRE Directive, Legal framework, Implementation rules, Data protection, Environmental data

\section{Introduction}

Spatial data relates to any direct or indirect reference to specific locations or geographical areas. In the EU such data have been difficult to find online at either a member state (MS) or EU level (EC 2016). The data were often poorly documented and curated in incompatible formats, which made data difficult to use. In addition, no generally available online services were available to enable people to find, access, use and share their spatial data within the country and across borders. Pan-EU spatial data infrastructure (SDI) of any kind did not exist before the INSPIRE Directive of 2007 (EC 2007).

The EU INSPIRE Directive of 2007 establishes an infrastructure to enable the sharing of spatial data and services in the EU to support environmental policies (EC 2007). INSPIRE was designed to address five identifiable challenges in relation to environmental policies and data (EC EEA 2014). These challenges include: (1) spatial data that were often missing or incomplete; (2) the absence of metadata description and documentation of the spatial data; (3) the inability to combine spatial data sets; (4) the absence of systems to find, access and use spatial data compatible with other datasets and, (5) cultural, institutional, financial and legal barriers that prevented and delayed the sharing and reuse of existing spatial data.

${ }^{1}$ Faculty of Education, Science, Technology \& Mathematics, University of Canberra, Canberra, Australia

${ }^{2}$ Faculty of Social Sciences, Katholieke Universiteit Leuven, Public Governance Institute, Leuven, België

*Corresponding author, email George.cho@ canberra.edu.au
There is a need to evaluate and reflect on the progress and challenges in the successful implementation of INSPIRE. Foremost in this review is the focus on legal and policy issues. The reason for this focus is that many of the identified issues have ironically both hindered and helped the development of a truly European SDI. MS with different legacies, histories and legal traditions have produced various responses and reactions to the implementation of INSPIRE. Overall, a conclusion may be that there are common concerns requiring resolution at an EU level.

This paper focuses on the legal issues arising from the Implementation Rules (IR) and the transposition of the INSPIRE Directive to MS legislation. The central focus suggests that legal issues may have hindered the smooth implementation of the Directive. This paper consists of five parts and Part I begins with a discussion of the background to the legal framework of INSPIRE. Then Part II shifts its attention to the legal issues that were identified in the INSPIRE 2014 Mid-term Evaluation Report while Part III examines the policy issues identified in the 2016 Commission's Report on the implementation of INSPIRE to the Council and European Parliament. Part IV reports on four case studies of the implementation of the Directive in member states (MS). Part V draws together emergent policy imperatives of the Directive including the role of INSPIRE in fostering good governance, use and sharing of environmental data and information for the common good of all Europeans.

\section{Legal frameworks}

The INSPIRE Directive provides the legal framework to achieve its stated objectives. How these objectives are 
achieved is left to Member States (MS) to decide in terms of the transposition of the Directive into national laws (EC 2007).

Each MS in the EU has its own legal structures comprising the legislatures, laws and administrative divisions. Some of these MS organisational structures have centralised governance while in others the structure may be devolved to municipal government. Legal traditions among MS vary from codified civil law to common law and to other customary rules and regulations. These differences and complexities among various MS have probably led to difficult challenges in attempting to transpose the INSPIRE Directive into MS legislation (Vandenbroucke et al. 2011; INSPIRE Country Reports at http://inspire. ec.europa.eu/webarchive/index.cfm/pageid/6/list/4.html).

Apart from the legal structures, the assembly, storage, use and sharing of geospatial data in the EU have also been varied and complex. Annoni (2007) has observed that in the EU there are islands of data of different standards and quality and that there is a dire need for a legal framework to help manage the differences (Annoni 2007). The 'legal framework' refers to EU legislation and pertinent legal and quasi-legal material or documents. Each MS has specific laws, codes and other legal instruments for regulating judicial procedures concerning the environment and environmental data. In the majority of the MS, these regulations apply nationwide. In some MS, however, legislation may be wholly regional or split between the national and regional. For example, apart from the more well-known federal states of Germany and Spain, MS also need to address different levels of governance such as Belgian law which is applicable nationwide but there are specific regulations for the regions of Brussels, Flanders and Wallonia (Gabele 2008). Denmark has a common legislation for the mainland, but has separate regulations for Greenland and Faroe Islands (Denmark 2008; and at http://inspire.danmark.dk/for-the-euenglish/the-danish-act/ accessed 17 July 2017).

Thus, it would be informative to compare the different styles of governance and government structure within the EU. Such reflections may inform how the variety of agencies involved may have helped or hindered the implementation of the INSPIRE Directive and its transposition into domestic laws.

\section{Mid-term evaluation report on INSPIRE Implementation 2014}

The European Commission published the Mid-term Evaluation Report on INSPIRE Implementation as required under Art.23 of the Directive (EC EEA 2014). The mid-term evaluation is based on various reviews, and self-evaluations by individual MS. Of the seven sections in the Mid-term Evaluation Report, two are of special interest for present purposes. Section four reviewed the state of implementation from legal transposition to coordination and IR, use of the infrastructure, estimated costs and benefits and a summary of the state of implementation. Section five examined the links to other environmental legislation and environmental policies especially the environmental acquis and INSPIRE. These two sections are reflective of the restrictions of governing rules and data policies as well as communication and coordination between MS and data protection. For the sake of completeness, the other sections in the Report are (1) Introduction; (2) Key elements of the INSPIRE Directive; (3) Methodology; (6) Links to other policies and activities and, (7) Results of the assessment. The following discussion on IRs and communication and the private sector address identified concerns.

\section{Implementing Rules}

To ensure that the SDIs of the MS are compatible and usable in a community and transnational context, the INSPIRE Directive requires adherence to common IRs (EC 2005). The IR reflect Commission Decisions that are binding in their entirety. The process of adopting such rules is monitored by a regulatory committee composed by representatives of the MS and chaired by a representative of the Commission (Comitology procedure). Non-binding Technical Guidelines specify how legal obligations could be implemented with reference to appropriate technical geospatial standards (EC 2005).

The Mid-term Evaluation Report addressed global issues relating to metadata, network services, the INSPIRE geoportal and the interoperability of spatial data sets and services. These concerns were identified as pertinent to the implementation process when dealing with how to cope with technological advances, the legal instruments to be used, questions of scale and data resolution.

Some MS have raised reservations about the possible 'restriction on technological advances' (EC 2008). The Commission response to MS reservations reiterates that the framework legislation defines the core content and expected functionality of INSPIRE components. These core content and components are independent of technological progress and are written in generic terms so as to adapt to changes and developments that ensure longterm fitness for purpose. The generic language in the policy is assisted by the non-binding Technical Guidance that spells out detailed implementation procedures and references to existing standards, technologies, and practices. These technical guidance documents are to be revised as required during implementation to consider the evolution of technology, new requirements, and resource allocation and budgets (EC 2008).

Some MS was concerned that there might be the need for different legal instruments for different IR. While the Commission has accepted the possibility that different legal instruments could apply to different IR, the exceptions and considerations are dependent on circumstances on a case-by-case basis. Any ensuing MS legislation is dependent on the nature of the measures contained in the IR and whether the provisions permit the modification of the relevant legislation within the MS (EC 2008). Some MS have observed that selected IR came into force on different dates and so are not in the same order as the building the infrastructure (EC 2010). Perversely the legal conundrum is that if the product was already in place before the IR there may be the need to revise the production process either by halting or slowing it down to satisfy the IR. The IR would not apply where the production has already taken place.

Scale and resolution issues arising from the spatial data have also been topics of concern. Queries have been raised by some MS such as: (1) grounds for excluding local authorities from participation in INSPIRE, for 
example, those below District Council in the UK; and, (2) legal requirements for the collection of data by local government relevant to an SDI (Open Rights Group UK 2009). The Directive explicitly states that local authorities must participate in INSPIRE if there is a relevant legal requirement to collect or publish data according to Article 4, Paragraph 6 (EC 2007) of the INSPIRE Directive.

The INSPIRE framework legislation mandates punitive action to be taken for non-compliance and/or late implementation. For the record one MS transposed the Directive on time while the Commission commenced infringement cases against $26 \mathrm{MS}$ for failing to adopt measures in time for transposing the Directive. By 2014 for five MS cases have been withdrawn before the transfer to the Court of Justice of the EU, 19 other MS have had their cases closed before a court ruling and a further two MS have been subject to court rulings for non-communication (EC EEA 2014). In sum, all $28 \mathrm{MS}$ have transposed INSPIRE into domestic law and communicated the text to the European Commission.

The European Commission conducted the necessary conformity assessment studies in the second half of 2013 after domestic laws had been fully communicated by the MS. EU pilot projects on conformity have been conducted since 2014 but the Commission has yet to begin any infringement procedures with regard to incorrect or bad application of INSPIRE in MS either on its own initiative or on the basis of formal complaints received (EC EEA 2014). As of April 2014, 14 Member States were involved in EU pilot studies where INSPIRE measures seem to be missing in the domestic laws, and/ or where they seem to have been incorrectly or incompletely transposed. The pilot projects explore the level of effort required to satisfy the IR for the INSPIRE Directive. For seven Member States, the dialogue in the pilots clarified the issues and the cases closed except for two MS (EC EEA 2014).

As the INSPIRE mindset has matured and MS become more appreciative of the benefits of the endeavour, the thinking has shifted to full implementation and maintenance on a continuing basis. An INSPIRE expert group on Maintenance and Implementation Framework (MIF) was set up in 2013 (INSPIRE MIG 2013). The INSPIRE Maintenance and Implementation Group (MIG) comprises national contact point representatives and a pool of experts from the stakeholder community. The main task of the MIG is to address issues and changes requested by INSPIRE stakeholders. The MIG is made up of two permanent sub-groups, one for addressing political aspects and evolution of INSPIRE vis-à-vis its relationship with other policies, and one for addressing technical issues (INSPIRE MIG 2013).

\section{Communication and the Private Sector}

The Mid-term Evaluation Report observed the lack of communication and coordination between some stakeholders within MS (EC EEA 2014). The challenge for the European Commission is to adequately inform stakeholders in the respective MS of interrelated initiatives within the EU and how these may affect the future implementation of INSPIRE. Some examples of initiatives within the EU include the Shared Environmental
Information System (SEIS) (EC Communication 2008). SEIS is a collaborative initiative together with the European Economic Area (EEA) and 39 countries of the European Information and Observation Network (EIONET) (http://www.eionet.europa.eu/reportnet). Another initiative is the Structured Implementation Information Frameworks (SIIF). SIIF seeks to improve the workability of environmental legislation through better online information (http://ec.europa.eu/environment/legal/pdf/platfor m/4st_meeting/Casaer_2014_SIIF_concept.pdf). The EU SEIS Implementation Outlook fosters improvements in the streamlining of EU reporting requirements such as monitoring the implementation of EU environmental legislation, public access to environmental information and public participation in the collection and dissemination of environmental information (http://ec.europa. eu/environment/archives/seis/pdf/seis_implementation_ en.pdf).

Three other examples of EU initiatives related to INSPIRE are: (a) the Small Medium-scale Enterprises (SME)-INSPIRE (smeSpire) project as a source of data provisioning (http://www.smespire.eu/). This initiative is an EU 7th Framework Programme (FP7) Support Action funded project to enable and encourage participation of private SMEs in making environmental data available, and to leverage the opportunities afforded by INSPIRE and related technologies such as Linked Open Data, Sensor Web and cloud computing. A collateral objective is to turn the challenges of the implementation of INSPIRE into business opportunities for the geo-ICT European SMEs. (b) Projects in the FP7 for Research and Technological Development and, (c) the EU Horizon 2020 which provide grants to researchers in Europe and beyond to co-finance research, technological development and demonstration projects (https://ec.europa.eu/research/fp7/ understanding/fp7inbrief/what-is_en.html and https://ec. europa.eu/programmes/horizon2020).

A disinterested observer may suggest that the initiatives noted above appear to address similar topics. Furthermore, the conclusion could be drawn that the policy landscape may have become more complicated and crowded thereby making it difficult to secure the necessary interest and support of stakeholders within MS. It may also be suggested that during the implementation phase post2007 the global financial crisis of 2008 may have persuaded MS to aim only to meet minimum compliance requirements of INSPIRE due to other priorities and domestic requirements.

The Mid-term Evaluation Report concluded that the coordination and communication among and between different MS could be improved. There could be a reduction of the administrative burden through simpler data sharing, awareness raising, capacity building and training for public sector officials involved in the programme. The Mid-term Evaluation Report also adds that the private sector should be encouraged to participate to a greater extent than it has (EC EEA 2014). It may be observed from the Mid-term Evaluation Report that while the private sector has been mentioned several times in the report, only once has the private sector been identified as a data provider and data user (EC EEA 2014). A future aspiration for INSPIRE could be one where both the private sector and private individuals become the first sources of raw data obtained through crowd-sourcing (Robbrecht 2016). 


\section{Data Protection}

The Mid-term Evaluation Report referred to links to other policies and activities such as the re-use of public sector information and other non-environmental EU policies and activities. However, reference to data protection has been overlooked in the Mid-term Evaluation Report despite being the topics of discussion at implementation workshops in 2008 and 2010. Arguably, data protection (privacy issues) are pertinent and pressing issues; especially where geographic information tools may permit the easy triangulation of data to create new information relating to a natural person even though the original data has masked personal details (EC 2010). At the 2010 workshop, the Commission provided the view that protective legal framework already exists (EC 2010). The Commission referred to the guidance released by the United Nations Economic Commission for Europe (UNECE) (2009) Principles on confidentiality and privacy aspects of statistical data integration (http://www.unece.org/stats/documents/ ece/ces/2009/3.e.pdf.) While the INSPIRE framework defines statistical confidentiality principles, the framework does not include 'data integration' or 'data matching' in the context of data protection.

Data protection within INSPIRE may become a major topic of contention among MS especially with the availability of fine-scale cadastral and parcel data where plot dimensions could be matched with revenue data that inherently contain ownership and identifiable personal details. Such data matching and synthetic datasets could morph into intractable privacy concerns in the future especially where a mature fully developed INSPIRE infrastructure permits the easy conflation of datasets that may be used for nefarious purposes.

The Mid-term Evaluation Report has since been followed up by a Commission Report to the Council and European Parliament (EC 2016). The later report focuses on policy especially regulatory fitness in terms of the effectiveness, efficiency and relevance of INSPIRE. We turn to this report next to continue the review of the implementation of the INSPIRE Directive and experiences to date.

\section{Commission report to the council and European parliament (EC 2016)}

The Commission reported to the Council and the European Parliament on the implementation of the Directive as required under Art 23 of the INSPIRE Directive (EC 2007). Shortcomings of the implementation of the Directive were identified in the light of the evaluation under the Regulatory Fitness and Performance Programme (REFIT). REFIT is designed to identify regulatory and other burdens, inconsistencies, gaps and measures deemed ineffectual (EC Communication 2012).

The Commission Report identified that only one MS transposed the directive into national legislation on time and nine MS had not transposed the Directive in a fully compliant manner (EC 2016). The major reasons for the delays have been attributed to political determination, administrative delays and changes in government. The Commission Report observed that the effectiveness of national coordination efforts was varied among MS.

Annex 1 of the INSPIRE Directive outlines five implementing steps. These are: (1) the transposition of the Directive into national legislation; (2) the identification of spatial data relevant for environmental policies; (3) documenting spatial data so that it may be accessed on the Internet together with other metadata; (4) implementing interoperable online services that allow for discovery, visualisation and downloading of spatial data and, (5) organising and publishing spatial data in common data models for greater interoperability and productivity (EC 2007).

For the record, the Commission Report identified shortcomings collated from experiences reported by MS themselves. These included the following: (a) the ineffective collaboration in some MS between national mapping agencies and environmental information bodies; (b) the variability and heterogeneity in national data sharing policies; (c) the wide flexibility of approaches available under the Directive from the fully open and free access and use to the full cost recovery and (d) the absence of non-government organisations, private agencies and quasi-government bodies in contributing to the corpus of geospatial environmental data to the collection (EC 2016).

In the section on regulatory fitness, the Commission Report has suggested that some 'less advanced' MS have regarded environmental issues low on the priority list of policies and that competition with parallel national policies on open data and eGovernment may have diverted attention from the full implementation of INSPIRE (EC 2016).

Several other important environmental projects should be noted here. The EU Location Framework (EULF) promotes location-enabled e-government across Europe, as part of the Interoperability Solutions for Public Administrations (ISA) programme (https://e3p.jrc.ec.europa.eu/ publications/european-union-location-framework accessed 4 Aug 2016). While INSPIRE provides the legislative framework focussed on the environmental sector, the Copernicus programme has made large amounts of earth observation data readily available (http://copernicus.eu/).

The European Location Framework (ELF) project (2013-2016) has delivered a pan-European cloud platform and web services to build on the existing work of the INSPIRE Directive and enable access to harmonised data in cross-border applications (http://www.elfproject.eu/). Norway and Finland are developing pan-European infrastructure and products that incorporate harmonised core geospatial data aimed at easier cross-border applications. The ELF is a Competitiveness and Innovation Framework Program (CIP) funded project (http://ec.europa.eu/digitalagenda/en/ict-policy-support-programme.)

From the above, it is argued that the nature of EU governance in using Directives to achieve policy goals may unintentionally have caused bottlenecks in the implementation of INSPIRE. There may be 'too many balls in the air to juggle' in terms of too many Directives that either have a similar subject matter (data) or similar end goals (data-sharing). Arguably, one could identify other directives including the Data Protection (Directive 95/46/EC) [superseded by the General Data Protection Regulations 2016 (Regulation 2016/679)], Public Access to Environmental Information (Directive 2003/4/EC9), Public Participation (Directive 2003/35/EC10), Re-use of Public Sector Information (Directive 2003/98/EC11) and Public Sector Information (Directive 2013/37/EU).

The Commission Report on implementation concluded that the overall relevance of the INSPIRE Directive to meet policy needs in an efficient manner remains high and is expected to increase over time. Good progress is 
correlated with investments in wider national policies, open data and better eGovernment services (EC 2016). The observed conclusion is that investments in infrastructure and people will result in greater progress in implementation and gains from the benefits of the Directive. Political willingness of the ruling government in power may also play as important a part as other policy and technical issues.

In recommending the next steps ahead, the Commission report exhorted that greater effort at all levels by all actors is needed in future from local government to MS and the Commission (EC 2016). What has occurred so far appears to be one approach where much of the legal, technical and policy initiatives have been from the top down. Equally, it may be observed that a further implementation stage could be to have the process initiated at the grass-roots level. The private sector 'prod-user' crowd-sourced data has so far been neglected in implementing INSPIRE (Budhathoki et al. 2008). The term prod-user has been used to describe the relationship between users and producers of information in the sense of both a producer and user of geospatial data. As noted previously, crowd-sourcing and volunteered geographic information (VGI) may be seen in the future to be important sources of raw, highly needed and useful geospatial data.

The Commission Report recommended a review and possible revision of INSPIRE IR for spatial data harmonisation with the aim of speeding up the process (EC 2016). We observe that this possibility may be a highly unsettling policy shift either where the IR are changed or new IR are developed because the so-called lagging MS may be left even further behind and may totally fail to keep up with the other more progressive MS. Any proposal to 'shift the goal posts' ex-post begs deeper considerations and regard for the negative consequences of such a proposal. The recommended changes may punish those MS that are either ahead or on schedule with the implementation of INSPIRE.

It is further observed that the Directive, as it is applied within the EU, is highly inward-looking having only a small regard for non-EU countries. Non-EU countries will have to conform to the Directive if they wished to share their data with an EU counterpart. Perversely, data sharing with non-EU countries may only occur after an independent review and advisory recommendation is made by the Article 29 Working Party (http://ec.europa. eu/newsroom/just/item-detail.cfm?item_id $=50083$ ) and accepted by the Commission. The perceived synergies and economic benefits in the international sharing of environmental data globally with countries such as the US and Canada, Australia and New Zealand have been recognised. The INSPIRE Directive may ironically risk a halt to the sharing of data and services between EU and the rest of the world.

\section{Implementation case studies}

The survey by Masser and Crompvoets (2015) demonstrates salutary lessons on the implementation of the Directive. The survey of four national case studies illustrates the range and diversity of approaches that have been used and deployed by MS to implement the Directive. Experiences from Denmark, Spain, the UK and Croatia demonstrate that there is no single blueprint for the development and implementation of national SDI in Europe as might be expected in an undertaking as wide in scope and as significant an endeavour as this is. To take account of national circumstances and the manner existing administrative responsibilities for geographic information are distributed between relevant agencies, each country has developed special agencies to be responsible for INSPIRE matters. These are the Danish Geodata Agency, Consejo Directivo de la Infraestructura de Información Geográfica en España (CODIIGE) in Spain, UK INSPIRE Compliance Board and the Croatia State Geodetic Administration, respectively.

A further means of dealing with the sub-national level of the implementation of the INSPIRE Directive is the shifting of responsibilities from federal to local government agencies. In Denmark, an association of 97 municipalities and the State work in conjunction with FOTdanmark to ensure that geospatial data are shared and developed between and within agencies at different levels of the governance structure (Denmark 2008). FOTdanmark is an association to create uniform digital maps of Denmark. In Spain, responsibilities have been delegated to 17 autonomous communities and two autonomous cities under the CODIIGE (http://www. idee.es/en/web/guest/codiige). In the UK, SDI responsibilities reside within the four constituent parts of the kingdom - England, Scotland, Wales and Northern Ireland. The UK INSPIRE Compliance Board, as a decision-making body, supports the Department for Environment Food and Rural Affairs (Defra) in its role as lead Department for UK INSPIRE implementation. Technical assurance is provided by the Architecture and Interoperability Board (https://data.gov.uk/ location/contact_points). These sub-national implementation agencies reflect the relatively mature stage of SDI development in these countries. Croatia, a member of the EU since 2013, also developed a central government SDI that is devolved to 21 counties within which are found 127 cities and 429 municipalities (see Hećimović et al. 2014).

Masser and Crompvoets (2015) have observed the benefits through INSPIRE by way of open data and egovernment. Especially in Denmark and the UK but to a lesser extent in Spain because of different organisational structures and uneven implementation by the responsible agencies. In Croatia, open data are still at a nascent stage of development. The benefits brought about through INSPIRE are have been recognised by public and private agencies and are deemed to have been vicariously responsible for growth and innovation in the respective MS.

Masser and Crompvoets (2015) highlighted the importance of geoportals developed under INSPIRE for delivering spatial services. Denmark and Spain have reported an increased use of the geoportal for data viewing, discovery services and download facilities. The UK country report noted the low level of network services. The Croatian geoportal launched in September 2014 may yet have an impact that could attract comment at this stage.

The discussion of legal issues arising from the Commission Report of 2016 and the case studies reported above may need to defer to policy imperatives. This is because national policy imperatives drive legislation together with the rules and regulations for implementing geospatial policies. There is, therefore, a need to discuss what 
the policy challenges and imperatives are and it is to these that we turn to next.

\section{Policy challenges}

Some of the major legal aspects of the implementation of the Directive have already been identified in the implementation Workshops held in 2008 and 2010. The Evaluation Report in 2014 further recognised the difficulties arising from the INSPIRE legislative framework and the problems some MS have faced in adapting national legislation in the transcription process (EC EEA 2014). Transcribing EU Directives into national rules means having to change national institutional practices.

The INSPIRE Directive provides a degree of harmonisation for environmental data but this brings with it inherent risks. As foreseen in the EULF Strategic Vision, such risks have already been identified in INSPIRE (http://ec.europa.eu/isa/actions/documents/isa-2.13_eulfstrategic-vision-lite-v0-3_final_en.pdf). As a concept, the EULF is an EU-wide, cross-sector interoperability framework for the exchange and sharing of location data and services for e-government services. The EULF complements and extends the implementation of INSPIRE to facilitate the introduction and use of the infrastructure within new thematic sectors (https://joinup.ec.europa.eu/ community/eulf/home).

The risks identified in implementing the INSPIRE Directive include:

- The risk of a lack of financial resources in a climate where it might be difficult for MS to achieve beyond the compliance requirements of INSPIRE.

- The risks that MS may not wish to change established practices as each may have their own requirements and approaches to e-Government and INSPIRE.

- The risks that the potential overlaps with other European geographic information initiatives (INSPIRE, ELF), may make it difficult either to establish a distinct identity for the EULF or secure engagement and backing. Since 2016 the ELF became an operational service named as the European Location Services (ELS). Ownership of the ELS has been transferred to EuroGeographics and its members: European National Mapping, Cadastre and Land Registry Authorities (http://www.eurogeographics. org/content/european-location-services accessed 17 July 2017).

- Risks where stakeholders may not perceive the benefits of a cross-sector or cross-border coordinated approaches.

- The possible risks in missing important implementation policies and procedures because of the broad range of stakeholders and initiatives, the dynamic nature of the landscape, and the difficulty of covering all eventualities.

- The risks that technical and administrative skills may not be available to implement good practices.

Policy challenges to the INSPIRE Directive can now be summarised below from experiences of MS and our observations. An omnipresent policy challenge is the rapid pace of developments in information technology (IT) practice. However, given new storage systems and methodologies and the cost-effective availability of storage in the cloud' there could be some in-built flexibility in the INSPIRE legislative framework. Such flexibility may allow for adjustments to innovations which at the same time are sufficiently robust to counter any collateral and unintended effects of the legislative framework.

A second challenge may arise from legacy data that cannot be made compliant to the requirements of INSPIRE for technical and historical reasons. This means that such data must be archived and in some cases may not be used for statutory purposes in future. Such an outcome may run counter to the ideals of the Directive (Carlisle 2014). The unintended result could be a 'loss' of valuable historical data collected and accumulated over time. This dilemma was also raised in the adoption of a geologic data model for Spain (Cerdan et al. 2012).

A third challenge is that of capacity building not only within agencies of respective MS but also the whole European community of data users and providers. Perversely the legal demands of INSPIRE dataset requirements may have excluded many data providers because of its complex needs (Carlisle 2014). Furthermore, some data providers or distributors may not be data creators such as those from academia and other commercial interests. As noted by Carlisle (2014), some data providers may not fully appreciate the benefits of INSPIRE compliance and only undertake the process because it is a legal requirement to do so. It could be argued that a more powerful case may be made by ensuring that the policy dialogue is turned around to promote the awareness and importance of the principles of compatibility and accessibility through compliance instead of emphasising the primacy of the legal requirements of the INSPIRE Directive.

The INSPIRE Directive is an overarching framework for environmental data. There may be an unintended 'covering of the field'. For example, the Pitney Bowes White Paper (2010) observed that the Directive referred to geospatial data that is defined to include data with a direct or indirect reference to any aspect of location, space or geographical area. The phrase 'indirect reference' implies that any data that has a key or reference to geospatial data embedded within its dataset may be caught within the meaning used in the Directive.

From the above, we observe that the unintended result is that many environmental datasets will be covered within the Directive. The perverse outcome is that these identifiers or keys may pose serious data protection (privacy) concerns. Such issues were raised in the INSPIRE implementation Workshops in 2008 by Norway and France (EC 2008) and in 2010 by Germany (EC 2010). Data protection and privacy advocates have suggested that fundamental human rights could be compromised by the INSPIRE Directive when read in conjunction with the Data Protection and PSI Directives without any derogation of the laws (van Loenen et al. 2016).

A salutary lesson from the preceding discussion is that the IT world has now made possible the manipulation of data, creation of conflated data using data from various sources, and data analytics that could pose serious threats to the use and release of personal information. The INSPIRE Directive as a policy and legislative tool in relation to geospatial environmental data should be carefully deployed. The INSPIRE Directive framework could be further developed so that it becomes both internally coherent as well as externally robust to withstand any possible challenge in a conflict of laws between MS states and other nations. 
One conclusion is that as the INSPIRE infrastructure becomes more mature and developed it may be conceivable that there will be greater transnational transfers of geospatial and environmental data. Some of these data exchanges may be seamless where bilateral agreements are in place. But, there may be other transfers of data where the agreements take the form of licences. The prospect of having to administer and maintain these licences may raise issues of the legal interoperability of licences between MS. However, as Welle Donker (2016) has concluded, the issue of legal interoperability among MS has yet to be addressed in the INSPIRE Directive.

Legal interoperability for data refers to a compatible environment of laws, policies and agreements that permits the seamless exchange, combination and re-use of data between different organisations and countries (van Loenen et al. 2012). Legal interoperability means that there is an agreement on the legal regime for interpretation purposes. According to the GEO Data Sharing Working Group (2014) legal interoperability occurs: (1) when use conditions are clearly and readily determinable for each dataset; (2) the use conditions allow the creation and use of combined or derivative products and, (3) that the data may be legally accessed and reused without having to seek further authorisation from data creators (Geo Data Sharing Working Group 2014). Welle Donker (2016) proposed that the Creative Commons licence suite may provide a pathway to legal interoperability of licences for cross-border re-use of geospatial environmental data and in accordance with recommendations and guidelines of the European Commission (EC 2014).

\section{Summary and conclusion}

Spatial data have been difficult to find online at either a MS or EU level. The INSPIRE Directive establishes an infrastructure that enables the sharing of spatial data and services in the EU to support environmental policies. This paper evaluated the progress and challenges in the implementation of the Directive. Legal frameworks within each MS have been found to be varied and complex because of historical, legislative and governance structures which have helped and hindered the implementation of the Directive.

A mid-term evaluation report highlighted various issues in the legal transposition of the Directive into domestic law. The links with other environmental legislation and policies especially the environmental acquis drew attention to some IRs and the role of the private sector. Some MS have been concerned with the inflexibility and restriction on technological advances which are contained in the IRs and the need for different legal instruments for different IRs. Technical matters such scale and resolution of data sets were also of concern. More generally the report was satisfied with the mature mindset with MS becoming more appreciative of the benefits of the INSPIRE Directive.

However, the lack of communication and coordination between some stakeholders within MS as well as shortcomings in communicating interrelated initiatives with the EU have not assisted the progress towards full implementation and maintenance of INSPIRE. Moreover, the general policy landscape may have become more complex and crowded thus making it more difficult to sustain and maintain heightened interest in INSPIRE. The shift towards interests in data protection and the INSPIRE Directive may have diverted the attention of many MS.

The most recent Commission Report to the Council and European Parliament identified shortcomings when evaluating the INSPIRE Directive under the Regulatory Fitness and Performance Programme. Regulatory and other burdens, inconsistencies, gaps and measures deemed ineffectual were identified for immediate redress. Some of these challenges have been further documented in the four case studies of Denmark, Spain, the UK and Croatia. National circumstances and existing administrative arrangements for geospatial environmental data have been identified as key reasons for successful implementation. Investments in infrastructure, such as geoportals and open data, and human resources, have shown to result in greater progress in implementation and benefits as do political will of the government in power. An observed conclusion from the case studies suggests that the top-down approach of the legal, technical and policy initiatives should be matched with those from the grass-roots level in relation to data collection such as crowd-sourced data and from the private sector.

Transcribing EU Directives into national rules means having to adjust national institutional practices and policy challenges of a technical and operational nature. The need for the harmonisation of environmental data also brings with it inherent risks of various kinds financial resources, breakdown of established practices, overlaps with other EU geographic information initiatives, loss of benefits from uncoordinated cross-sector and/or cross-border approaches, missing important implementation policies; and the lack of technical and administrative skills. The rapid developments in IT, vis-à-vis legacy data, bring to the surface issues of incompatibility and loss of use. The challenge of building capacity in human and technical resources; data protection concerns, transfers of geospatial and environmental data globally, and the use of licences to circumvent legal interoperability have been brought to a head in the progress from implementation per se to maintenance of the infrastructure embodied in INSPIRE.

In summary, it is submitted that a major conclusion of this paper is that the INSPIRE Directive should be interpreted not as one of a set of legal requirements within a legislative framework but rather as one where adoption of high standards of principles and practice is a matter of course. The objective should not simply be about meeting legal obligations but of putting in place policies, processes and systems that result in continuous development and improvements in the capture of geospatial environmental data as well as the sharing and provisioning of geospatial products among MS. It is submitted that the INSPIRE Directive should be perceived as a set of processes that results in improvements in data integration, data quality and value-adding arising from interoperability and transferability of information. INSPIRE as an infrastructure for geospatial environmental data should aspire towards a sharing information society that drives key benefits for the whole community. 


\section{ORCID}

George Cho (D) http://orcid.org/0000-0002-9766-5732

Joep Crompvoets (i) http://orcid.org/0000-0003-1077$597 \mathrm{X}$

\section{References}

Annoni, A. 2007. Information Management in Environmental Sciences, Metier Graduate Training Course no.2, Monpellier, February, Available from: http://www.peer.eu/fileadmin/user_upload/opport unities/metier/course2/c2_management_dissemination_interoperab ility1.pdf.

Budhathoki, N., Bruce, B., and Nedovic-Budic, Z., 2008 Reconceptualising the role of the user of spatial data infrastructure. GeoJournal, 72, 149-160.

Carlisle, M. 2014. Implications of the INSPIRE Directive for SNH held Habitat Data. Scottish Natural Heritage Commissioned Report No. 698, Perth, Scotland.

Cerdan, F.P., Mancebo, M.J.M., and Pascual, F.R., 2012. The impact of the INSPIRE Directive on geologic data models of geological surveys, the IGME (Spain) case, 7th European Congress on Regional Geoscientific Cartography and Information Systems. EUREGEO 2012, Bologna, Italy, 12-15 ${ }^{\text {th }}$ June 2012.

Denmark. 2008. Infrastructure for Spatial Information Act, passed by the Danish Parliament 9 December 2008 (English translation). Available from: http://inspire.danmark.dk/for-the-eu-english/thedanish-act/ [Accessed 17 July 2017].

European Commission. 2005. Draft Guidelines for the Development of the INSPIRE Implementing Rules, Available from: http://www. ecgis. org/inspire/reports/dt/ir_draft_guidelines.pdf [Accessed 3 March 2017].

European Commission. 2007. Directive 2007/2/EC of the European Parliament and of the Council of 14 March 2007, establishing an infrastructure for spatial information in the European Community (INSPIRE), Brussels, 25.4.2007, Official Journal of the European Union (L108/1), Available from: http://inspire.jrc.it/ home.html.

European Commission. 2008. Report of the workshop on the Legislative Transposition of the INSPIRE Directive 2007/2/EC.

European Commission. 2010. Workshop on Legal Issues 17 June 2010 Brussels. Questions and answers on the implementation of the INSPIRE Directive 2007/2/EC.

European Commission. 2014. Guidelines on recommended standard licences, datasets and charging for the reuse of documents, Official Journal of the European Union, C240/01: 10. Available from: https:// ec.europa.eu/digital-agenda/en/news/commission-notice-guidelinesrecommended-standard-licences-datasets-and-charging-re-use.

European Commission. 2016. Report from the Commission to the Council and the European Parliament on the Implementation of Directive 2007/2/EC of March 2- 7 establishing an Infrastructure for Spatial Information in the European Community (INSPIRE) pursuant to article 23, Brussels, 20.7.2016 COM(2016) 478 Final

European Commission Communication. 2008. Towards a Shared Environmental Information System. Available from: http://eur-lex. europa.eu/LexUriServ/LexUriServ.do?uri = COM:2008:0046:FIN: EN:PDF.
European Commission Communication. 2012 on the Regulatory Fitness and Performance Programme (REFIT) on evaluating and reducing administrative burden (COM(2012) 746 Final).

European Commission and European Environment Agency. 2014. Midterm Evaluation Report on INSPIRE Implementation, Joint EEAJRC Technical report No. 17/2014 Report EUR 91574 EN.

Gabele, F. 2008. The implementation and the transposition of the INSPIRE Directive within the Belgian Federal context, FIG Open Symposium, Verona, Fiere 14 September 2008. Available from: https://www.fig.net/resources/proceedings/2008/verona_am_ 2008_comm7/ppt/14_sept/5_1_gabele.pdf [Accessed 11 Aug 2016].

GEO Data Sharing Working Group (GEO DSWG). 2014. White Paper: Mechanisms to Share Data as Part of GEOSS Data-CORE. Available from: https://www.earthobservations.org/documents/ dswg/Annex $\% 20 \mathrm{VI}^{\circ} \% 20-\% 20 \% 20$ Mechanisms $\% 20$ to $\% 20$ share $\%$ 20data $\% 20$ as $\% 20$ part $\% 20$ of $\% 20$ GEOSS $\% 20$ Data_CORE.pdf.

Hećimović, Ž, Marasović, S., and Crompvoets, J., 2014. Development of local spatial data infrastructure in Croatia. Journal of Spatial Science, 59 (2), 221-234. DOI: 10.1080/14498596.2014.908424.

INSPIRE Maintenance and Implementation Group (MIG). 2013. Available from: https://inspire.ec.europa.eu/MIG-Work-Programme/ Maintenance-and-Implementation/46 [Accessed 4 Aug 2016].

Masser, I., and Crompvoets, J. 2015. 'Four National Case Studies. Progress on INSPIRE Implementation', GeoInformatics, January/ February 2015, pp.22-24.

Open Rights Group UK. 2009. Consultation on the transposition of EC Inspire Directive 2007/2/EC into UK law. Available from: http:// www.openrightsgroup.org.

Pitney Bowes. 2010. Meeting the Obligations of the EU INSPIRE Directive: White Paper \#1, Considerations for Public Sector Organisations. Available from: https://www.pitneybowes.com/ content/dam/pitneybowes/germany/de/legacy/docs/International/ CE/software/pdf/Branchenl\%C3\%B6sungen/INSPIRE_White_ Paper_1_PDF_REV01_Final_21_09_10.pdf.

Robbrecht, J. 2016. INSPIRE boosts spatial data sharing GIM e-Newsletter 2 June 2016, Available from: https://www.gim-international.com/ content/article/inspire-boosts-spatial-data-sharing.

United Nations Economic Commission for Europe (UNECE). 2009. Principles on confidentiality and privacy aspects of statistical data integration. Available from: http://www.unece.org/stats/documents/ ece/ces/2009/3.e.pdf.

Vandenbroucke, D., et al., 2011. Spatial Data Infrastructure in Europe: State of Play Spring 2011. Leuven: Spatial Applications Division, K.U. Leuven Research \& Development.

van Loenen, B., Janssen, K., and Welle Donker, F., 2012. Quest for a global standard for geo-data licences GSDI 13 World Conference Global Geospatial Conference 2012: Spatially enabling government, industry and citizens, Québec City, 14-17 May 2012. Available from: http://repository.tudelft.nl/view/ir/uuid\%3Aca7682be-9bca-47d9-8d 29-0db047051cb5/.

van Loenen, B., Kulk, S., and Ploeger, H., 2016. Data protection legislation: a very hungry caterpillar: the case of mapping data in the European Union. Government Information Quarterly: An International Journal of Information Technology Management, Policies, and Practices, 33, 338-345.

Welle Donker, F., 2016. From access to re-use: a user's perspective on public sector information availability. PhD dissertation concept, July, TU Delft. 